\title{
Evaluasi Kesuksesan Sistem Informasi Pelaporan dan Monitoring Kota Layak Anak dengan Model Design-Reality Gap
}

\author{
Evaluation of the Success of the Reporting and Monitoring Information System \\ of Child-Friendly City With the Design-Reality Gap Model
}

\author{
Kursehi Falgenti ${ }^{*}$, Atikah Mardi ${ }^{2}$, Ana Ruemardiana ${ }^{3}$ \\ ${ }^{1}$ Program Studi Sistem Informasi, Fakultas Ilmu Komputer, Universitas Nusamandiri Jakarta \\ ${ }^{2,3}$ Program Studi Teknik Informatik Fakultas Teknik, Universitas Indraprasta PGRI Jakarta
}

\begin{tabular}{l}
\hline ARTICLE INFO \\
\hline Article history: \\
DOI: \\
10.30595/pspfs.v1i.146 \\
Submitted: \\
June 28, 2021 \\
Accepted: \\
July 10, 2021 \\
Published: \\
Oct 31, 2021
\end{tabular}

Keywords:

Reporting and Monitoring, Model design-reality gap, evaluation of information system success

\begin{abstract}
The Child-Friendly City web-based reporting and monitoring information system was implemented at the end of 2018 in Depok City. Through the web address, http://kla.depok.id Child-Friendly City cadres could report activities of child-friendly city forums based on five clusters and 29 indicators. The public could find information on Depok City as well as a child-friendly city. After three years of implementation, evaluation was necessary to ensure that the information system operates according to the initial design. This study aimed to evaluate the success of the monitoring and reporting information system for the Child-Friendly City of Depok. The evaluation was done by looking at the gap between the initial design of the system and the reality of the system's current state. The evaluation method was a gap analysis using a design-reality gap model consisting of 7 dimensions of Information, Technology, Process, Goals and Values, Staff placement and skills, management systems and structures, and other resources (ITPOSMO). The evaluation results showed that the information system failed partially. A recommendation for improvement was proposed so that Child-Friendly Cities' reporting and monitoring information system does not fail miserably. This recommendation aimed to make the reporting and monitoring process for the childfriendly city of Depok more effective.
\end{abstract}

This work is licensed under a Creative Commons Attribution 4.0 International License.

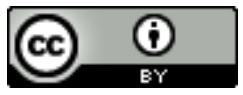

Corresponding Author:

Kursehi Falgenti

Program Studi Sistem Informasi, Fakultas Ilmu Komputer, Universitas Nusamandiri Jakarta

J1. Jatiwaringin No. 2, Cipinang, Melayu Makasar Jakarta Timur

Email: falgenti.kfe@nusamandiri.ad.id

\section{PENDAHULUAN}

Lembaga Forum untuk Kota Layak Anak Depok (FOKLA) Depok merupakan sebuah lembaga berdedikasi pada pembangunan kota ramah terhadap tumbuh kembang anak dalam upaya mempercepat terwujudnya masyarakat yang sehat lahir batin. Mulai tahun 2018 pemerintah kota depok memfasilitasi FOKLA aplikasi web untuk mendukung aktivitasnya melalui alamat www.kla.depok.go.id. Pada web ini disediakan layanan pelaporan dan monitoring kegiatan. Bagi pemangku kepentingan di Kota Depok halaman web ini berfungsi memonitoring aktivitas kader FOKLA. Laporan kegiatan melalui layanan berbasis web untuk mengurangi penumpukan dokumen, dan membuat data menjadi terpusat dengan dukungan basis data terintegrasi. Keterlambatan pengumpulan laporan diharapakan tidak terjadi karena pengguna aplikasi web di Kecamatan, dikelurahan dan di RW hanya mengunggah laporan berdasarkan klaster-klaster dan indicator-indikator yang telah ditentukan.

Sistem monitoring menurut Amsler, dkk (Amsler et al., 2015)bertujuan memastikan suatu proses dilakukan sesuai prosedur yang berlaku, menyediakan probabilitas tinggi akan keakuratan data bagi pelaku monitoring, dan 
mengidentifikasi hasil yang tidak diinginkan pada suatu proses. Menurut Tery (Terry, 2014) difinisi monitoring sebagai determinasi apa yang telah dilaksanakan, bila diperlukan untuk mengevaluasi prestasi kerja, menerapkan tindakan-tindakan korektif sehingga hasil pekerjaan sesuai dengan rencana yang telah ditetapkan.

Selain sebagai pusat data laporan dan monitoring, layanan berbasis web ini merupakan sumber informasi kota ramah anak yang dapat diakses oleh publik. Aktivitas dalam sistem informasi publik milik pemerintah Kota Depok ini dilakukan oleh banyak pengguna mulai dari kader RW, penggerak tingkat kelurahan, dan kordinator tingkat kecamatan. Kegiatan FOKLA yang terdistribusi di banyak RW dan banyak kelurahan, didukung oleh komunitas menjadi alasan bagi pemerintah depok mengimplementasikan sistem monitoring dan sistem laporan terintegrasi pada tahun 2018. Sistem informasi ini bertujuan untuk memastikan kegiatan-kegitan di tiap RW di Kota depok kota ramah terhadap tumbuh kembang anak dalam upaya mempercepat terwujudnya masyarakat yang sehat lahir batin dapat dilaporkan dan dimonitor.

Sistem informasi yang baru diimplementasikan di organisasi tidak begitu saja diterima oleh pengguna. Berbagai tanggapan dari pengguna terhadap sistem informasi baru adalah gembira, tidak peduli, skeptis, dan takut (Bhattacherjee et al., 2017). Penerimaan dan penolakan merupakan dua dikotomi dalam literatur implementasi sistem informasi. Teknologi Informasi diterima bukan hanya produk tapi juga prosesnya (Lapointe \& Beaudry, 2014). Niat sebagai perilaku pada penerimaan Teknologi Informasi tidak hanya didefinisikan sebagai niat seseorang untuk menggunakan TI tetapi juga niat untuk mengadopsinya (Bhattacherjee et al., 2017), untuk digunakan kembali (Turel et al., 2008), untuk terus menggunakan (Limayem et al., 2007), dan kembali ke situs web (Koufaris, 2002). Tingkat penggunaan yang tinggi salah satu factor kesuksesan sistem informasi.

Teknologi internet memudahkan pengguna mengakses layanan, namun demikian bukan berarti pengguna akan selalu menggunakannya. Kendala seperti transfer pengetahuan tidak berlangsung dengan baik dan siklus hidup proses seperti control, implemnetasi, dan monitor aktivitas proses yang tidak berjalan semestinya (Scheruhn et al., 2020) berkontribusi sebagai penyebab gagalnya sistem informasi. Layanan berbasis web memungkinkan aplikasi diakses menggunakan perangkat komputer desktop atau laptop. Perkembangan teknologi web 2.0 telah menjadikan halaman web interaktif dan dinamis, menghasilkan berbagai jenis aplikasi mendukung operasional perusahan dan organisasi, Kemudian dengan berkembangnya teknologi mobil. layanan aplikasi terdistribusi berbasis mobil menjadikan aplikasi lebih fleksibel dapat diakses dari berbagia perangkat dan interoperabilitas yag tinggi. layanan tidak hanya dapat diakses di browser komputer tapi juga dari perangkat mobil melalui program aplikasi.

Investasi sistem informasi Sebagian besar dimotivasi oleh kebutuhan untuk menghasilkan produk dan pelayanan dengan nilai yang lebih baik melalui rantai pasok yang kuat dan responsif. Dalam teori seharusnya investasi pada sistem informasi bisa memberikan keuntungan seperti yang banyak disampaikan dalam literatur. Terminologi "productivity Paradoks" adalah istilah untuk menggambarkan dugaan ketidakmampuan teknologi informasi menghasilkan keuntungan dan manfaat yang dijanjikan dalam teori (Brynjolfsson \& Hitt, 1998). Terminologi ini masih relevan pada saat ini (IRANI, 2008). Untuk memastikan sistem informasi berjalan sesuai tujuan pengembanganya, memastikan keberlanjutannya dan untuk apakah terjadi productivity paradoks diperlukan evaluasi menyeluruh pada sistem informasi laporan dan dan monitoring bebasis web. Dari hasil evaluasi banyak informasi yang diharapkan dapat digunakan sebagai dasar usulan perbaikan sistem informasi agar efektif digunakan oleh para kader menunjang aktivitas kegiatannya.

Penlitian ini bertujuan melakukan evaluasi kesuksesan sistem pelaporan dan monitoring kegiatan kota layak anak Depok. Evaluasi ini untuk melihat seajuh mana tujuan implementasi sistem informasi dapat dicapai. Dari hasil evaluasi dapat dirancang alternatif solusi untuk meningkatkan kesuksesan sistem informasi ini. Evaluasi bermafaat sebagai pembalajaran organisasi, namun ini belum terjadi (IRANI, 2008). Metode evaluasi yang digunakan adalah gap analisis menggunkan model design-reality gap (Hawari \& Heeks, 2010) . Model ini dikembangkan untuk mengevaluasi implementasi sistem informasi di negara berkembang dengan melakukan komparasi antara rancangan awal sistem informasi dengan keadaan sistem yang sudah beroperasi. Berdasarkan hasil evaluasi menggunakan model designreality gap, kemudian disusun rekomendasi pengembangan sistem informasi laporan dan monitoring untuk mendukung kesuksesan program Kota Depok yang ramah anak.

Studi tentang evaluasi kesuskesan sistem informasi menggunakan model design-reality gap jarang ditemukan dalam literatur karena model ini dikembangkan untuk evaluasi kesuksesan sistem infomasi di negara berkembang. Beberapa penelitian evaluasi sistem informasi menggunakan model design-reality gap diantaranya: Hawari dan Heeks dalam penelitianya menjelaskan kegagalan parsial yang terjadi pada sebuah perusahaan yang dinilai gagal mengimplementasikan ERP (Hawari \& Heeks, 2010). Menjelaskan kesuksesan implementasi ERP di salah satu UMKM (Falgenti \& Mai, 2014) Menemukan sumber kegagalan Sistem Manajemen Kartu subsidi di Kerala, India Selatan (Masiero, 2016). Mengevaluasi secara sosial dan teknis tantangan digitalisasi layanan penyuluhan pertanian di Ethiopia (Atinaf et al., 2020). Menguji tingkat kesiapan sistem pendidikan menengah Ethiopia yang terintegrasi teknologi komunikasi informasi (TIK) untuk pendidikan berkualitas (Bati \& Workneh, 2021). 


\section{METODE PENELITIAN}

Metode penelitan untuk mengevaluasi sistem informasi laporan dan monitoring FOKLA depok adalah metode analisis kesenjangan menggunakan model design-relaity gap. Model ini terdiri dari tujuh dimensi pengukuran; Information, Technology, Process, Objective and values, Staffing and skill, Management System and structure dan Other resource disingkat dengan ITPOSMO. Penjelasan dari masing-masing dimensi sebagai berikut. Informasi: penyimpanan data, alur data, dan lain-lain. Teknologi: perangkat keras dan perangkat lunak. Proses: aktivitas user dan yang lain. Tujuan dan Nilai: faktor yang terlibat seperti budaya dan politik. Penempatan dan kemempuan staf: keduanya adalah aspek kuantitatif dan kualitatif dari kompetensi. Sistem manajemen dan struktur. Sumberdaya yang lain: khususnya waktu dan uang. Hasil dari evaluasi menggunakan model ini adalah sistem informasi gagal total, gagal parsial, dan sukses dengan penjelasan yang medukung.

Metode pengumpulan data dan analisa data yang digunakan adalah triangulasi (menggunakan beberapa metode pengumpulan dan analisa data). Triangulasi untuk meningkatkan validitas data agar data yang digunakan untuk dianalisa adalah data yang bermanfaat [16]. Pengumpulan data primer dilakukan melalui: pertama melihat bagaimana penggunaan sistem informasi dengan mengakses sistem laporan dan monitoring kota layak anak dan mempelajari bagaiman sistem tersebut bekerja. Kedua wawancara dengan orang kader FOKLA Kota Depok, Wawancara difokuskan untuk untuk mengetahui kondisi sistem informasi laporan berbasis web pada saat penelitian dilakukan (existing) dan bagimana sistem informasi ini dapat mendukung kader FOKLA mengirim laporan. Ketiga, analisa dokumen buku manual petunjuk penggunaan sistem informasi laporan dan monitoring kota layak anak dan proposal sistem informasi laporan dan monitoring kota layak anak,untuk mengetahui tujuan awal dan spesifikasi sistem yang disulkan diawal.

\section{HASIL DAN PEMBAHASAN}

\section{Proses bisnis sistem laporan dan monitoring Kota laya anak Depok}

Dari hasil diskusi dengan kader dilapangan dapat diketahui cara kerja sistem informasi pelaporan dan monitoring berbasis web. Mereka beralih dari cara kerja laporan yang selama ini manual menjadi laporan melalui aplikasi website. Buku manual penggunaaan aplikasi dibagikan untuk semua kader. Masing-masing kader telah mempelajari buku petunjuk tersebut.

Pada sistem informasi yang bersifat mandatory seperti di kla.depok.go.id, dimana pengguna tidak mempunyai pilihan lain. Pengguna dengan persepsi negatif dipaksa untuk menggunakannya terlepas dari preferensi pribadi mereka. Namun, sistem mandatory seperti itu sering menyebabkan ketidakpuasan, moral rendah, dan resistensi di pihak pengguna, menurun produktivitas, efektivitas, dan kualitas kerja di bagian organisasi, dan terkadang kegagalan proyek implementasi.

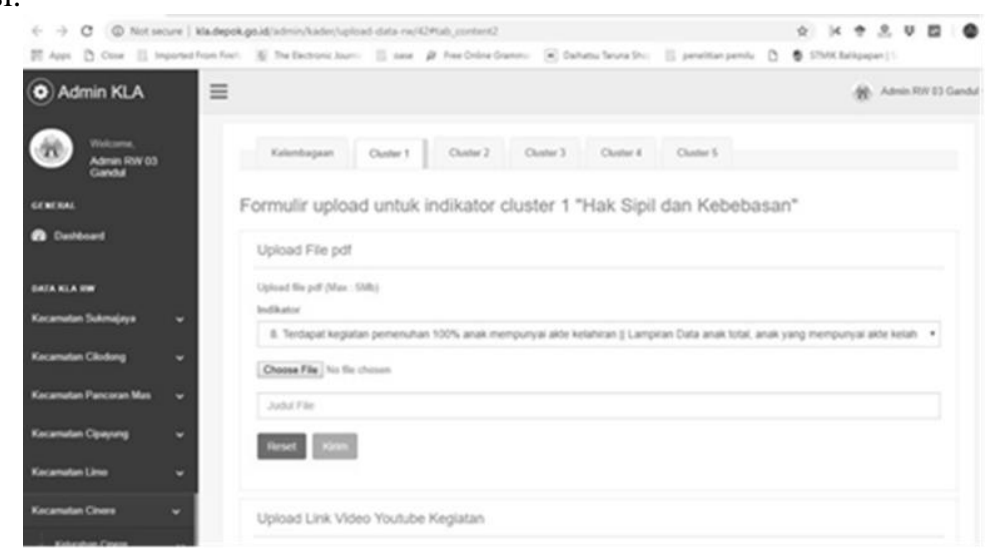

Gambar 1. Form laporan kegiatan

Pemerintah Kota Depok memutuskan pekerjaan dilakukan dengan dukungan website sifatnya mandatory untuk memudahkan proses laporan kegiatan organisasi. Kader membuat dan mengunggah laporan menggunakan komputer atau laptop. Pada tahun 2019 Jumlah kader yang terlibat dalam sistem laporan ini terdiri 11 kader tingkat kecamatan, 62 kader ditingkat kelurahan. Tidak semua RW di masing-masing keluarahan yang memiliki kader Kota Ramah anak, rata rata ada 2 RW yang memiliki kader, jadi untuk tingkat RW terdapat 112 kader. Perkiraan total pengguna aplikasi pelaporan dan monitoring ini sebanyak 185 orang di tahun 2019. Seiring dengan bertambahnya pengurus gugus tugas di beberapa kelurah dan RW, saat ini pengguna sistem semakin banyak

Cara kerja sistem pelaporan dan monitoring berbasis web adalah : Kader di RW mengisi form berdasarkan 29 indikator penilaian yang telah dibagi menjadi 5 klaster di halaman kla.depok.go.id (gambar 1). Masing-masing penilaian disediakan tautan untuk mengunggah dokumen sebagai data pendukung. Kemudian laporan ini diperiksa oleh kader ditingkat kelurahan, setelah lengkap diteruskan kepada kader tingkat kecamatan. Baru kemudian rekap 
laporan tersebut muncul di dashboard (gambar 2 gambar 3). Kader juga dapat mengirimkan berita acara kegiatan. Barita ditulis kemudian dijadikan file dengan format pdf disertai photo kegiatan kemudian dikirim lewat email ke admin di tingkat kecamatan. Nanti admin akan menampilkan acara kegiatan tersebut di halaman web sebagai berita untuk publik. Kordinator dimasing-masing kecamatan memonitor seluruh aktivitas pelaporan, memastikan tidak terjadi kesalahan input laporan dan mengingatkan kader yang belum mengungah laporan.

Untuk memastikan kondisi sistem informasi sesuai dengan rancangan implementasi di awal dilakukan evaluasi menggukanan model design-reality gap.

\section{Analisa kesenjangan \\ Informasi}

Rancangan informasi: Informasi dihalaman web menampilkan kegiatan-kegiatan yang menunjukkan Kota Depok sebagai kota yang ramah terhadap tumbuh kembang anak. Sedangkan laporan dalam bentuk file memberikan informasi lengkap kegiatan-kegiatan yang dilakukan baik di tingkat RW, tingkat kelurahan dan ditingkat kecamatan berdasarkan indikator pada masing-masing klaster. Masing-masing masing kordinator ditingkat kecamatan dan penggerak di tingkt kelurahan bertanggung jawab terhadap laporan kegiatan di daerahnya.

Realitas informasi: setelah diimplementasikan sistem informasi laporan dan monitoring kota layak anak Depok ini dapat menampilkan berita kegiatan-kegiatan yang menunjukkan kota depok sebagi kota yang ramah terhadap tumbuh kembanga anak. Namun, berita yang ditampilkan tidak update, berita terakhir ditulis tahun 2019. Setelah tahun 2019, tidak ada lagi berita kegiatan yang muncul di homepage. Menu pada aplikasi web sangat simple memudahkan pengguna web menelusuri informasi di halaman web. Homepage juga menampilkan slider informasi profil gugus tugas Kota layak anak. Data-data kota layak anak dibagi dalam 5 klaster pengguna dapat memilih data layak anak menggunakan filter berdasarkan kecamatan, kelurahan dan RW. Informasi data kegiatan belum dalam bentuk format yang standar. Nama file laporan sesuai dengan nama kegiatan tapi didalam file hanya ada foto tidak memuat informasi kapan, dimana, siapa dan keterangan yang menjelaskan fota kegiatan yang dilaporkan.

\section{Teknologi}

Rancangan teknologi: aplikasi web dirancang untuk dapat diakses dengan cepat melalui browser dan didukung dengan interface yang mudah dioperasikan oleh pengguna. Halaman web dapat diakses dari berbagai perangkat mulai dari komputer, laptop, tablet, dan perangkat mobil android. Melalui aplikasi dapat di-unggah dokumen laporan kegitan dengan format MS office maupun pdf.

Realitas teknologi: aplikasi web dapat diakses dengan cepat dari browser dan interface memudahkan pengguna mengapload laporan. Format file laporan yang bisa diupload hanya jenis file dengan ekstensi pdf. Aplikasi web sudah didukung dengan template yang responsif, bisa dibuka diberbagai jenis perangkat mobil. Namun, beberapa fungsi pada applikasi web seperti unggah dokumen tidak muncul saat dibuka di browser menggunakan perangkat mobil android. Jadi untuk meng-unggah laporan harus menggunakan laptop atau PC. Software yang digunakan untuk mengembangkan fungsi unggah dokumen memiliki keterbatasan tidak support dengan aplikasi browser perangkat berbasi android.

Proses

Rancangan proses: Semua pengguna yaitu seluruh kader di RW, penggerak di kelurahan dan kordinator di kecamatan melaporkan setiap kegiatan dengan meng-unggah file laporan melalui aplikasi web. Masing-masing kordinator kecamatan mempubkasikan setiap kegitan di wilahnya. Informasi berita kegiatan berupa foto kegiatan dan penjelasan dengan narasi singkat disampaikan saat meng-ungguah laporan kegiatan, agar kordinator bisa menerbitkan berita kegiatan di halaman depan web. Penggerak dan kordinator di masing-masing leurahan dan kecamatan melakukan monitoring terhadap laporan-laporan yang masuk

Realitas proses: fungsi monitor oleh kordinator dan penggerak sepetinya tidak berjalan. Laporan kegiatan yang tidak lengkap bisa lolos. Dengan format laporan yang tidak lengkap informasi kegiatan tidak tersampaikan dengan sempurna, kredibilitas informasi diragunakan karena tidak memenuhi format $5 \mathrm{~W}+1 \mathrm{H}$, karena itu tidak layak diberitakan. 


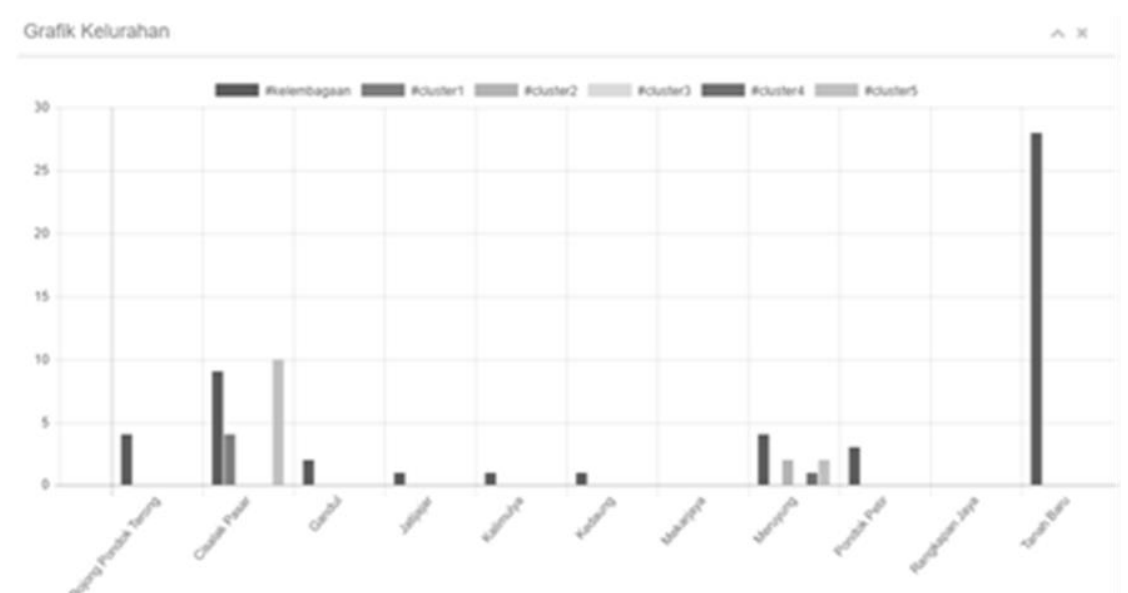

Gambar 2. dashboard laporan perkecamatan tahun 2019

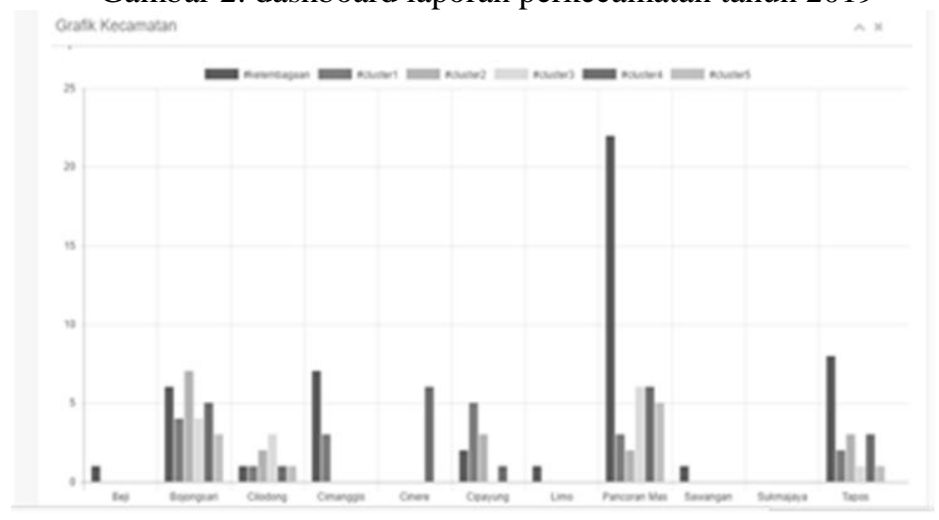

Gambar 3. dashboard laporan per kelurahan tahun 2019

Perilaku pengguna menanggapi cara kerja baru dengan dukungan website ini ternyata beragam, ada yang mau terlibat ada yang tidak mau terlibat. Ini bisa dilihat dari jumlah laporan yang masuk. Berdasarkan data di dashboard Tahun 2019, setahun setelah implementasi laporan yang masuk sangat sedikit hanya Kecamatan Pancoran Mas yang telah meng-unggah laporan lebih dari 50\% (gambar 2) data laporan yang diunggap oleh kelurahan sangat sedikit sekali (gambar 3). setelah beberapa tahun website beroperasi sudah banyak laporan yang masuk. Laporan per klaster dari admin di kecamatan sudah ada tapi belum lengkap. Beberapa kader belum meng-unggah laporan untuk masing-masing klaster secara lengkap. Di tingkat kelurahan laporan juga tidak lengkap, ditemukan hanya ada laporan lengkap di dua klaster sedangkan klaster lainnya laporannya tidak di-unggah.

\section{Tujuan dan nilai:}

Rancangan Tujuan dan nilai: sistem informasi ini bertujaun ntuk mendukung kota Depok layak anak. Untuk mencapai tujuan diperlukan media informaasi yang terpercaya. Pemerintah Kota Depok mengimplementasi sistem informasi ini karena program kota layak anak menjadi program prioritas.

Realitas: Sistem informasi telah berhasil diimplementasikan dan aplikasi telah digunakan oleh kader menyampaikan laporan dan kegiatan di daerah masing-masing. Nilai-nilai gotong royong dan bekerja sama memajukan Kota Depok yang dipegang para kader merupakan salah satu faktor yang medorong sistem pelaporan dan monitoring ini bisa berjalan sampai saat ini. Komitmen dari pimpinan daerah menjadikan Depok sebagai kota ramah anak dapat dipahami dan ikut memotivasi kader dan penggerak dibawah.

Penempatan dan kemampuan.

Rancangan Penempatan dan kemampuan: kader di tingkat RW adalah ujung tombak program Kota Depok layak anak. Mereka mengikuti sosialisasi tentang Kota Depok layak anak dan pelatihan penggunaan aplikasi web untuk suksesnya program depok kota layak anak.

Realitas penempatan dan kemampuan: Kader pengerak ditingkat bawah adalah pemuda dan pemudi yang telah dilatih dan mendapatkan pengetahuan tentang kota ramah anak. Mereka telah mengikuti sosialisasi tentang program Depok sebagai kota layak anak dari tim gugus kendali terdari dari berbagai elemen masyarakat di Kota depok dan mengikuti sosialisasi penggunaaan sistem laporan dan monitoring kota layak anak. Pemahaman akan program dan bentuk kontribusi yang dibutuhkan para kader disosialisasikan agar kader mengetahui tugas dan tanggung jawabnya agar sistem informasi pelaporan dan monitoring dapat beroperasi mensukseskan Kota Depok sebagai kota layak anak. 


\section{Sistem dan struktur manajemen}

Rancangan sistem dan struktur manajemen: Untuk mewujudkan Kota layak anak Depok akan di bentuk gugus tugas di bawah tanggung jawab Sekda. Struktur kepengurusan dari kecamatan sampai ke tingkat RW akan dibantuk. Sistem informasi laporan dan monitoring dirancang berdasarakan struktur kepengurusan forum kota layakanak depok dari kecamatan sampai ke RW.

Realitas sistem dan struktur manajemen: SK penugasan diberikan kepada kader di tingkat RW, penggerak di tingkat kelurahan dan kordinator di tingkat kecamatan. Dengan adanya SK ini tugas dan tanggung jawab masing-masing pihak lebih jelas dan dibawah kordinasi pemerintahan Kota Depok

\section{Sumber daya lain}

Rancangan sumberdaya lain: Anggaran pengembangan yang memadai merupakan salah satu factor keberlanjutan suksesnya sistem informasi. Anggaran untuk implementasi dan operasional sistem informasi peleporan dan monitoring disediakan oleh pemeritah Kota Depok.

Realitas sumber daya lain: anggaran yang mencukupi salah satu factor berasilnya implementasi dan adopsi sistem informasi peaporan dan monitoring kota layak anak. Selanjutnya perlu dipkirkan bagaimana pengembangan sistem informasi ini kedepan.

\section{Hasil evaluasi}

Hasil proses evaluasi menggunakan tujuh dimensi ITPOSMO menunjukkan kesenjangan pada dimensi infomasi; berita di halaman web tidak udate dan laporan yang disampaikan tidak lengakap. Informasi yang disampaikan hanya sebatas nama kegiatan dan foto kegiatan. Dihalaman web tidak ditemukan Informasi pendukung kota layak anak. Hanya ada nomor kontak instansi DPAPMK, informasi nama kordinator ditingkat kecamatan tidak ditemukan. Informasi akun media social juga tidak ditemukan. Pada dimensi teknologi. Teknologi software yang digunakan memilki keterbatasan, tidak mendukung unggah dokumen dari perangkat mobil berbasis android. Kesenjangan pada dimensi proses fungsi monitor tidak berjalan, fungsi monitor dan kontrol merupakan aspek penting dalam siklus hidup aktivitas proses dalam sistem informasi. Pada dimensi lainnya tidak ditemukan kesenjangan, menunjukkan sistem informasi pelaporan dan monitoring sudah sesui dengan rancangan awal. Pada dimensi yang belum sesuai rancangan awal direkomendasikan perbaikan memastikan pelaporan dan monitoring berjalan efektif.

\section{Rekomendasi pengembangan sistem}

Dalam rancangan awal, sistem infomasi pelaporan dan monitoring ini dibangun berbasiskan web. pengembangan sistem informasi laporan dan monitoring kota layak anak dapat dilakukan dengan membangun aplikasi mobil berbasis android untuk memudahkan para kader bekerja mengunggah laporan. Namun membutuhkan anggaran. Usulan yang mungkin dilakukan adalah membangun sistem pendukung laporan untuk para kader di tingkat RW dan penggerak di tingkat kelurahan. Sistem pendukung laporan ini adalah aplikasi google keep dan ggoogle drive.. Google Keep adalah aplikasi catatan yang dapat dibuka disemua perangkat yang terhubung dengan akun google. Apikasi Google Keep dapat digunakan diperangkat PC laptop, smartphone, tablet. Dengan menggunakan aplikasi Google Keep pengguna dapat berbagi catatan dengan pengguna Google keep lain. Berbagai pakai catatan dengan menambahkan akun google lain sebagai kolaborator pada catatan tersebut. Dengan fitur yang dapat menambahkan kaloborator ini Google keep dapat digunakan mendukung kolaborasi dan kordinasi melakan update berita. Sedangkan Google drive merupakan media penyimpanan tersentralisasi milik google. melalai google drive penguna dapat berbagi pakai file berkolaborasi secara online menyelesaikan berbagai pekerjaan.Proses laporan pada sistem pendukung pelaporan dan monotring Kota layak anak Depok ini akan dibuat lebih sederhana (Gambar 5), dimana proses laporanya dapat dilakukan menggunakan perangkat smartphone.

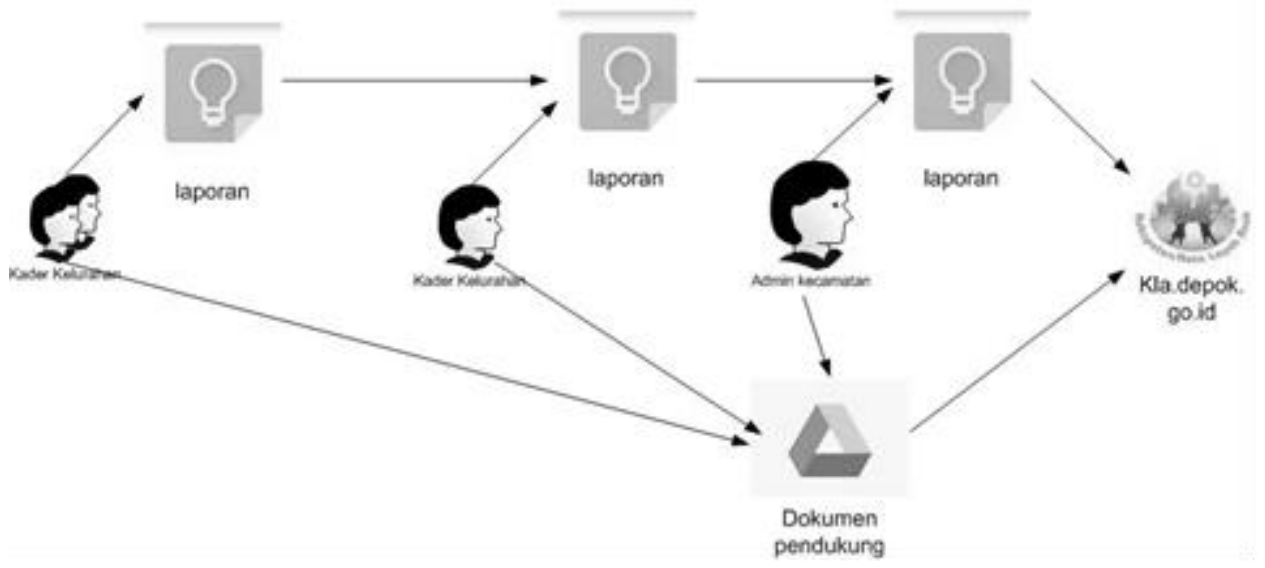

Gambar 4. Rancangan sistem pendukung pelaporan dan monitoring

Dokumen pendukung penilaian indiator di 5 klaster penilaian di simpan di google drive. Bila ada video kegiatan pendukung utuk penilaian di 5 klaster di simpan di youtube. Masing-masing kader RW menggunakan google keep 
mencatat poin yang dinilai berdasarkan indikator yang telah ditentukan (Gambar 1). Link file pendukung berupa dokumen yang sebelumnya disimpan di google drive dan link video yang sebelumnya disimpan di akun youtube, di copy pada google keep (gambar 4). Setelah pencatatan laporan dan data pendukung lengkap kader ditingkat RW mengundang kader ditingkat kelurahan dengan menambahkan akun googlenya sebagai kolaborator pada catatan tersebut. Setalahh menjadi kolaborator kader ditingkat kelurahan memiliki aksess membaca catatan diaplikasi Google Keep berupa laporan dari kader ditingkat RW. bila masih ada kekurangan pada laporan, penggerak ditingkat kelurahan dapat meminta kader ditingkat RW melengkapi catatan laporannya. Setelah lengkap kader FOKLA tingkat kelurahan kemudian mengundang kader tingkat kecamatan menjadi kolaborator pada catatan yang ditulis oleh kader tingkat RW. Pemeriksaan akhir dilakukan oleh penggerak tingkat kecamatan. Setelah lengkap pengerak tingkat kecamatan dapat membuka web kla.deok.go.id dan mengisi form survey untuk RW yang membuat catatan laporan kegiatan sesua dengan klaster yang dinilai, menyalin link tautan vidio sebagai bukti kegiatan, dan mendownlod dokumen pendukung dari link yang dibuat oleh kader tingkat RW dalam catatan di aplikasi Google Keep. Kemudian mengunggah kembali ke kla.depok.go.id

\section{KESIMPULAN}

Hasil evaluasi menunjukkan sistem informasi pelaporan dan monitoring gagal parsial. Sebagai salah satu bentuk mitigasi menghindari sistem ini gagal total penelitian ini merekomendasikan penggunaan aplikasi peningkatan produktivitas seperti google keep dan google drive mendukung pelaporan dan monitoring. Kedua aplikasi ini memudahan kader FOKLA Depok melakukan pekerjaan-pekerjaan profesional yang sebelumnya hanya bisa dilakukan di komputer. Aplikasi google keep dan perangkat smartphone dapat membantu meringkas proses pelaporan kegiatan, diharapakan cara baru ini sementara dapat membantu aktivitas FOKLA. Sedangkan untuk peningkatan layanan sistem informasi pelaporan dan monitoring dapat dilakukan dengan membangun alikasi web yang dinamis dengan dukungan aplikasi hybrid.

\section{DAFTAR PUSTAKA}

Amsler, G. M., Findley, H. M., \& Ingram, E. (2015). Guidance for the Modern Workplace. Supervision, 76(1), 1521. https://elibrary.ru/item.asp?id=4352158

Atinaf, M., Molla, Alemayehu; Karanasios, S., \& Anteneh, S. (2020). Digitalizing Agriculture Extension Service in Ethiopia: a Design-reality Gap Analysis. Proceedings of the 24th Pacific Asia Conference on Information Systems: Information Systems (IS) for the Future.

Bati, T. B., \& Workneh, A. W. (2021). Evaluating integrated use of information technologies in secondary schools of Ethiopia using design-reality gap analysis: A school-level study. Electronic Journal of Information Systems in Developing Countries, 87(1). https://doi.org/10.1002/isd2.12148

Bhattacherjee, A., Davis, C. J., Connolly, A. J., \& Hikmet, N. (2017). User response to mandatory IT use : a Coping Theory perspective. European Journal of Information Systems, March. https://doi.org/10.1057/s41303-0170047-0

Brynjolfsson, E., \& Hitt, L. M. (1998). Beyond the productivity paradox. Communications of the ACM, 41(8), 4955. https://doi.org/10.1145/280324.280332

Falgenti, K., \& Mai, C. (2014). Implementasi ERP Pada UKM dengan Design-Reality Gap Model : Studi Kasus Implementasi SAP B1 di PT CP. Jurnal Manajemen Teknologi, 13(3).

Hawari, A., \& Heeks, R. (2010). Explaining ERP failure in a developing country: a Jordanian case study. Journal of Enterprise Information Management, 23(2), 135-160. https://doi.org/10.1108/17410391011019741

IRANI, Z. (2008). Information systems evaluation: A crisis of understanding. In Evaluating Information Systems (Sixth Edit, Issue 2000). Elsevier Ltd. https://doi.org/10.1016/b978-0-7506-8587-0.50004-4

Koufaris, M. (2002). Applying the technology acceptance model and flow theory to online consumer behavior. Information Systems Research. https://pubsonline.informs.org/doi/abs/10.1287/isre.13.2.205.83

Lapointe, L., \& Beaudry, A. (2014). Identifying IT User Mindsets : Acceptance , Resistance and Ambivalence. https://doi.org/10.1109/HICSS.2014.568

Limayem, M., Hirt, S. G., \& Cheung, C. M. K. (2007). How habit limits the predictive power of intention: The case of information systems continuance. MIS Quarterly. https://www.jstor.org/stable/25148817

Masiero, S. (2016). The Origins of Failure: Seeking the Causes of Design-Reality Gaps. Information Technology for Development, 22(3), 487-502. https://doi.org/10.1080/02681102.2016.1143346 
Scheruhn, H. J., Bayramli, E., \& Hintsch, J. (2020). An enterprise information model for knowledge transfer with application systems: The current state of enterprise GPS. CSEDU 2020 - Proceedings of the 12th International Conference on Computer Supported Education, 2(Csedu), 278-289. https://doi.org/10.5220/0009365602780289

Terry, G. R. (2014). Guide to Management, Prinsip-prinsip Manajemen. In Jakarta: PT. Bumi Aksara.

Turel, O., Yuan, Y., \& Connelly, C. E. (2008). In justice we trust: predicting user acceptance of e-customer services. Journal of Management Information .... https:/www.tandfonline.com/doi/abs/10.2753/MIS0742-1222240405 